\title{
DESDE HACE NUEVE MESES FINLANDIA TIENE UNA VACUNA ANTI COVID-19, PERO APOYÓ A LAS GRANDES FARMACÉUTICAS*
}

Ilari Kaila

Joona-Hermanni Mäkinen ${ }^{\mathrm{b}}$

" DOI: https://doi.org/10.18601/01245996.v23n45.12. Publicado originalmente en Jacobin, 12 de 03 marzo de 2021, [https://jacobinmag.com/2021/02/ finland-vaccine-covid-patent-ip]. Recepción: 15-04-2021, aceptación: 0206-2021. Sugerencia de citación: Kaila, I y Makinen, J. H. (2021). Desde hace nueve meses Finlandia tiene una vacuna anti Covid-19, pero apoyó a las grandes farmacéuticas. Revista de Economia Institucional, 23(45), 257-264.

a Escritor y periodista independiente. Profesor en la Universidad de Ciencia y Tecnología de Hong Kong.

b Educador, escritor e investigador de la democracia económica y de historia económica. 
Desde hace nueve meses Finlandia tiene una vacuna anti Covid-19, pero apoyó a las grandes farmacéuticas

Resumen Moderna recibió 2.500 millones de ayuda pública en Estados Unidos. Los investigadores de la Universidad de Helsinki necesitaban 50 millones para la fase III de su vacuna libre de patentes. Pero no consiguieron ayuda del Estado, pese a que gobierna un partido socialdemócrata.

Palabras clave: Covid-19, vacunas, patentes, grandes farmcéuticas, financiación pública, ganancias privadas; JEL: I13, I28, I39

Finland Had a Patent-Free COVID-19 Vaccine Nine Months Ago - But Still Went With Big Pharma

Abstract Moderna received 2.5 billion in public support in the United States. Researchers at the University of Helsinki needed 50 million for phase III of their patent-free vaccine. But they did not get any help from the state, despite the fact that a social democratic party is in power.

Keywords: Covid-19, vaccines, patents, big pharma, public funding, private profit; JEL: I13, I28, I39

\section{A Finlândia tem uma vacina anti-Covid-19 há nove meses, mas apoiou uma grande farmácia}

Resumo Moderna recebeu 2,5 mil milhões de euros de apoio público nos Estados Unidos. Os investigadores da Universidade de Helsínquia precisavam de 50 milhões para a fase III da sua vacina sem patente. Mas não obtiveram ajuda do Estado, apesar do facto de um partido social-democrata governar.

Palavras-chave: Covid-19, vacinas, patentes, grandes fármacos, financiamento público, lucros privados; JEL: I13, I28, I39 
11 pasado mes de mayo, un equipo de destacados investigadores Cfinlandeses tenía lista una vacuna contra la covid-19 sin patente, que habría permitido que los países de todo el mundo inocularan a su población sin pagar mucho dinero. Pero en vez de apoyar la iniciativa, el gobierno finlandés favoreció a las grandes farmacéuticas, lo que muestra que el modelo de financiación basado en patentes pone las ganancias por encima de la salud pública.

"Pensamos que era nuestro deber empezar a desarrollar una alternativa de este tipo", dice el profesor Kalle Saksela, director del departamento de Virología de la Universidad de Helsinki. "En la primavera aún creía que alguna entidad pública se involucraría y empezaría a impulsarla. Pero al parecer ninguna situación es suficientemente urgente para que el Estado busque activamente algo semejante"

Desde mayo de 2020, el equipo de Saksela tenía lista una vacuna sin patente contra la covid-19, a la que llamaron "el Linux de las vacunas", en un guiño al famoso sistema operativo de código abierto que también se originó en Finlandia. El trabajo se basa en datos de investigación a disposición del público y en el principio de compartir todos los nuevos hallazgos publicados en revistas especializadas.

$\mathrm{E} 1$ equipo de investigación incluye algunos científicos muy conocidos en Finlandia, como el profesor del Instituto AI Virtanen Seppo Ylä-Herttuala, miembro de la Academia Finlandesa y antiguo presidente de la Sociedad Europea de Terapia Génica y Celular, y el académico Kari Alitalo, asociado extranjero de la Academia Nacional de Ciencias de Estados Unidos. Ellos sostienen que su aerosol nasal, basado en tecnología y conocimientos bien establecidos, es seguro y muy efectivo.

"Es un producto terminado, en cuanto la formulación no cambiará de ningún modo con más pruebas", dice Saksela. "Con lo que tenemos, mañana podríamos inocular a toda la población de Finlandia”.

Pero en vez de explorar el potencial de la investigación libre de propiedad intelectual, Finlandia, igual que otros países occidentales, siguió la política habitual de las últimas décadas: apoyar totalmente a la gran industria farmacéutica.

En el relato predominante, las vacunas anti Covid-19 de primera generación de Pfizer, Moderna y AstraZeneca se presentan como un ejemplo de la manera en que los mercados incentivan y aceleran la innovación esencial. Pero en la realidad, el hecho de que el afán de lucro sea el elemento principal en el desarrollo de la investigación médica ha sido devastador, en especial en una pandemia global. La vacuna finlandesa es un ejemplo sorprendente de la manera en que el 
modelo contemporáneo de financiación basado en patentes ha frenado el desarrollo de vacunas y cómo obstaculiza la posibilidad de realizar campañas eficaces de inoculación masiva.

\section{PROPIEDAD INTELECTUAL PRIVADA}

La necesidad de descubrir el próximo producto innovador patentado tiene efectos nocivos en la investigación. Incentiva a las empresas a ocultar sus hallazgos a las demás y a la comunidad científica en general, aun a costa de la salud humana. El objetivo del modelo de "código abierto"libre de propiedad intelectual es revertir esta situación y convertir la investigación en un esfuerzo colaborativo multilateral en vez de una carrera para inventar y reinventar la rueda.

En lo que respecta a la Covid-19, el efecto paralizante del modelo de financiación contemporáneo se hace sentir en forma más aguda en las etapas finales: la aprobación y el uso del producto final. El virólogo Saksela dice que el tiempo perdido en los primeros días de la pandemia debido a la falta de colaboración y a los secretos comerciales es casi insignificante. De hecho, el desarrollo de todas las vacunas anti Covid-19 de primera generación ha sido relativamente sencillo.

"La investigación preliminar terminó en una tarde y marcó la dirección para las demás", afirma Saksela. "Con base en lo que ya sabíamos del SARS-1 y el MERS, todo era bastante obvio - no un triunfo de la ciencia”. En vez de introducir un germen inactivado o debilitado en el cuerpo humano, las nuevas vacunas contra el coronavirus entrenan nuestro sistema inmunológico para que responda a una "proteína de espiga" -en sí misma, inofensiva- que forma las protuberancias características de la superficie del virus.

El conocimiento ampliamente compartido de este mecanismo es anterior a la contribución de las empresas farmacéuticas. Esto suscita preguntas sobre el impacto de la investigación orientada a las patentes en el producto final. ¿En qué medida el trabajo es guiado por la eficacia médica y en qué medida por la necesidad de mantener la propiedad de la patente?

"Las empresas de biotecnología colocan la proteína de espiga en un mecanismo de entrega, bien sea tecnología de ARN o alguna otra", explica Saksela."Y, en general, la elección se basa en las aplicaciones que tienen patentadas, sea o no la mejor opción".

La vacuna finlandesa utiliza un adenovirus que porta instrucciones genéticas para sintetizar la proteína de espiga. Una de sus ventajas prácticas es que, a diferencia de la tecnología de ARN basada en na- 
nopartículas lipídicas, se puede almacenar en un refrigerador normal, y quizá a temperatura ambiente. Esto facilita y abarata la logística de distribución, pues no se requiere almacenarla a temperaturas muy bajas. El equipo de Saksela considera que además de la estabilidad y la conveniencia de administración nasal, la vacuna puede tener otras cualidades superiores a muchas de las que hoy están en el mercado. "Para detener por completo la propagación del virus y librarnos de nuevas mutaciones, debemos inducir inmunidad esterilizante", es decir, que el virus deje de replicarse en el cuerpo de una persona por lo demás sana. Los ensayos preliminares parecen confirmar que el aerosol nasal la consigue. "En cerca de la mitad de las personas expuestas, asî sean asintomáticas, el virus sigue presente en el sistema respiratorio superior. De modo que así esté en vía de extinción, aún está activo y convierte al sistema inmunológico en una especie de compañero de entrenamiento".

Pero si la vacuna es tan buena como se anuncia, ¿qué la frena? Aparte de la gran industria farmacéutica y del capital de riesgo, quedan pocos mecanismos para financiar los ensayos con pacientes a gran escala que se necesitan para que una vacuna supere la línea de meta. Las patentes son monopolios avalados por el Estado que prometen rendimientos potencialmente enormes por la inversión. El modelo actual de financiación de la investigación farmacéutica se basa casi por completo en esa expectativa, y es aquí donde un producto médico libre de propiedad intelectual encuentra serios obstáculos.

Un ensayo clínico Fase III requiere decenas de miles de personas y costaría unos 50 millones de dólares. Pero si se tiene en cuenta que, pese al relativo éxito de Finlandia en el control del virus, el país ya ha tomado en préstamo 18.000 millones de euros adicionales para salir adelante, esa suma parece una gota de agua en el océano, pues no es más que una cuarta parte del porcentaje de deuda pública inducida hasta ahora por la pandemia. Una cifra irrisoria comparada con la pérdida de vidas humanas y la devastación económica en el planeta.

\section{EL ESTADO ALLANA EL CAMINO A LAS GANANCIAS PRIVADAS}

Esta situación es especialmente absurda si tenemos en cuenta que la llamada investigación farmacéutica privada es financiada en su mayoría con fondos públicos. Moderna recibió 2.500 millones de dólares de ayuda del gobierno estadounidense y aun así intentó desplumar a los compradores con precios exorbitantes. Pfizer se jacta de no haber recibido dinero de los contribuyentes, pero su campaña 
de relaciones públicas poco tiene que ver con la realidad: la vacuna se basa en aplicaciones de investigación pública desarrolladas por la firma alemana BioNTech, que ha recibido 450 millones de dólares de apoyo adicional del gobierno.

Estas cifras solo son la punta del iceberg cuando consideramos el capital que los países invierten anualmente en universidades, instituciones científicas, educación e investigación básica. Así es como se forma el conjunto de conocimientos y experiencia inherente a toda innovación.

"Por ejemplo, tenemos estos nuevos medicamentos biológicos, relacionados con las vacunas en sentido técnico-científico, producidos con la misma tecnología de ADN, cuyo precio es comparable a la extorsión", sostiene Saksela. "Es muy triste. La suma más alta que se pueda arrancar a una persona o al Estado es la que dicta el precio. Y, por supuesto, en últimas se basan en investigaciones financiadas con fondos públicos, como es el caso de las vacunas".

En otras palabras, pagamos dos veces por la misma vacuna: primero por su desarrollo y después por el producto final. Pero puede haber incluso un tercer precio, pues los gobiernos han aceptado asumir la responsabilidad de los posibles efectos secundarios de las vacunas contra el coronavirus. Se trata de una dinámica típica entre las grandes corporaciones y los Estados: las ganancias son privadas, los riesgos se socializan.

"Pero cuando intenté defender que Finlandia desarrollara su propia vacuna, el principal argumento que escuché fue: es necesario que tenga una entidad con hombros suficientemente amplios para asumir el riesgo", cuenta Saksela. "Pero todo eso es palabrería, porque las empresas exigen, y se les concede, exención de toda responsabilidad".

El actual sistema basado en el monopolio de las patentes es relativamente reciente, no un efecto secundario inevitable del capitalismo. Hasta finales de la década de 1940, los gobiernos financiaban la mayoría la investigación médica, mientras que el papel de las empresas farmacéuticas se limitaba principalmente a fabricar y vender medicamentos. Hoy, los gobiernos apoyan a las empresas en forma de subsidios y diversa privilegios monopólicos.

Los perjuicios van mucho más allá de la escasez y los altos precios. Por un lado, poner fin en seco a una enfermedad es un mal negocio. En un caso famoso, la firma de biotecnología Gilead vio caer sus ganancias en 2015-2016 debido a que su nuevo medicamento contra la hepatitis $\mathrm{C}$ terminó curando del todo a la mayoría de los pacientes. Esa misma estructura de incentivos perversos ha saboteado los esfuerzos 
para crear vacunas preventivas, pese a los llamados urgentes de los expertos en salud pública durante los últimos veinte años.

De haber invertido en investigación predictiva, el brote se podría haber detenido en China. En una entrevista con el New York Times, el profesor Vincent Racaniello del departamento de Microbiología e Inmunología de la Universidad de Columbia lo expresa sin rodeos: "La única razón por la que no la hicimos es porque no había suficiente respaldo financiero". Peter Daszak, especialista en ecología de las enfermedades y experto en salud pública, coincide con él: "La alarma se disparó con el SARS y pulsamos el botón de repetición. Luego volvimos a pulsarlo con el Ébola, con el MERS, con el Zika”.

Infortunadamente, aún no hay muchas señales de que los líderes políticos hayan despertado. Hay una escasez desesperada de vacunas, mientras que las empresas farmacéuticas luchan por dar abasto aun con sus propias estimaciones de producción. Esta es una consecuencia directa no solo de la inviolabilidad de las patentes, sino de que el juego está amañado contra soluciones creadas fuera del sistema basado en el lucro. Puesto que las vacunas solo se pueden producir en laboratorios de propiedad de los dueños de las patentes o autorizados por ellos, la mayoría de las fábricas farmacéuticas del mundo están ociosas. Una solución de emergencia propuesta por India y Sudáfrica, respaldada en la Organización Mundial del Comercio por la mayoría de los gobiernos, buscaba suspender los derechos de propiedad intelectual de las vacunas anti Covid-19. Los países ricos, encabezados por Estados Unidos y la Unión Europea, se negaron categóricamente.

Entretanto, los países ricos han hecho la mayor parte de los pedidos de vacunas. Dejando de lado la ética, es un modo desastroso de combatir una pandemia. Para empezar se producen cantidades inadecuadas de vacunas y se distribuyen según la riqueza y no con base en una política sensata de salud pública. Incluso los países ricos acaban disparándose en el pie. Pues se permite que el virus se siga propagando y mutando en la mayor parte del planeta.

Dentro de esta jerarquía global, Finlandia es uno de los países más privilegiados. Pero el cuello de botella en la producción de vacunas tiene efectos adversos en todos, incluidos los finlandeses. Como subraya el profesor Saksela, es fundamental empezar a tomarse en serio la preparación, a nivel nacional y mundial. El mundo está lejos de controlar la pandemia actual, y el hecho macabro es que la próxima solo es cuestión de tiempo. 
"Que todo se deje en manos de las fuerzas del mercado es un signo de los tiempos que corren", dice Saksela. "Habría que considerar al menos si es un enfoque acertado".

\section{¿PARAÍSO SOCIALDEMÓCRATA?}

Los medios de comunicación internacionales suelen presentar a Finlandia como un país de ensueño nórdico. Durante la pandemia, su nuevo gobierno de izquierdas ha reforzado la imagen progresista del país. Cabría esperar que tal gobierno sea el defensor más obvio de la tecnología de producción de vacunas financiada con recursos públicos, y compartida libremente. Pero las últimas décadas -la era neoliberal- dejan una larga sombra.

Reflejando la tendencia general de partidos afines, el Partido Socialdemócrata en el poder empezó a reestructurarse en la década de 1990 a imagen del Nuevo Laborismo de Tony Blair y de los Demócratas de Clinton. En 2003, Finlandia suspendió el programa nacional de desarrollo de vacunas - después de 100 años en funcionamiento- al mando de un ministro de Salud socialdemócrata, para dejar vía libre a las multinacionales farmacéuticas.

Aunque la vacuna ha recibido mucha atención en los medios de comunicación finlandeses, con una oposición mucho más hostil hacia el sector público que la de los partidos en el poder, hay poco debate sobre ella entre el establishment político. Y en vez de una financiación directa del Estado, Saksela y sus colegas han recibido un consejo del Ministerio de Asuntos Sociales y Salud: crear una startup y empezar a cortejar inversionistas de capital de riesgo.

Saksela tiene la esperanza de que aún puedan obtener la financiación necesaria. Pero esto significa aceptar, al menos en parte, la lógica incoherente de la investigación médica orientada al mercado: por muy bueno que sea tu producto o salve muchas vidas, salvo que pretendas ganar dinero, será muy difícil que despegue.

"Un ensayo Fase III seguirá generando propiedad intelectual en torno a nuestra vacuna, que consideramos potencialmente rentable", dice Saksela, "aunque no sea extorsivamente rentable". 